\title{
Gender Representation and Stereotypes in the K-12 English Learner's Materials
}

Ailel Suzzet D. Manalo

Department of Education, Division of City of San Fernando (P) Sindalan, City of San Fernando Pampanga, Philippines

\begin{abstract}
:
This research is a critical study, which intends to identify the gender representation and stereotypes present in the four K-12 English learner's materials for Junior High School in the Philippines. Using a content analysis and integrating the findings with the interview responses of selected teachers and students from the Division of City of San Fernando Philippines, the following inferences were generated: male characters showed far more visibility than female characters who also rarely came first in gender pairings; male characters were engaged in more active roles than the female characters who, as well, were often linked with occupations that required less leadership and knowledge-based skills and were low-income generating; female characters were often associated with negative traits, while male characters were often attached with positive traits; domestic roles were almost exclusively attached with female characters; and that there was no indication of gender variance or gender nonconformity in all the learner's materials analyzed. The researcher recommends that the K-12 English learner's materials for Junior High School may be revisited. The selection of the literary pieces may consider the works of female authors who penetrated the literary canon. Department of Education may require all textbooks and learner's materials writers, editors, and publishing companies that work for the department to attend seminars and trainings on gender sensitivity and inclusivity. Overall, these LMs may entail gender sensitivity and genderqueer inclusion.
\end{abstract}

Keywords: Gender representation, gender stereotypes, gender sensitivity, learner's materials

\section{Introduction}

The gender ideology of the Philippine society is patriarchal. Women are expected to act according to what the ideology of the family and domesticity, sex role socialization, and the ideology of the sexual division of labor dictate. Women are oppressed for they are delimited with the expectations structured by the society and with the stereotyped images of woman which is bounded to be the opposite of man. Women movements against oppression come into existence and make several attempts to improve their social condition. Feminists demand for equality and clamor for justice. They try to define and re-define women, creating different images of them. But these, instead of giving women their own identity, have caused confusion of who really women are. They now are more marginalized.

Amid the proliferation of uprisings against women oppression and the growing awareness of women's liberation, voices that are too often silenced and cast to side surface to interrupt and to challenge heteronormativity. In the mid of 1990s, the concepts of non-binary identity and expressions came into the picture. The term genderqueer, to refer to individuals who do not subscribe to conventional gender distinctions or whose gender identities cannot be categorized as solely male or female, has been popularly used. The issue is no longer just the privileging of masculinity and maleness over femininity and femaleness but includes issue of non-binary oppression. Transgender, genderfluids, gays, lesbians, polygenders, and other genders completely outside of men/women binary claim an equal share of the pains of gender oppression. They too are marginalized.

The gender situation in the Philippines is marked with contradictions. The state says there are equal opportunities for Filipino men and women. The 1987 Philippine Constitution, Declaration of Principles Article II Section 14 
asserts that "The state recognizes the role of women in nation-building and shall ensure the fundamental equality before the law of women and men." Article XIII Section 14 of the Labor Code expresses that "The state shall protect working women by providing safe and healthful working conditions taking into account their maternal functions, and such facilities and opportunities that will enhance their welfare and enable to realize their full potential in the service of the nation." Furthermore, Republic Act 9710 known as the Magna Carta for Women has been established to secure women's rights and to "eliminate discrimination through the recognition, protection, fulfillment and promotion of the rights of Filipino women especially those who belong in the marginalized sector. Lila Ramos Shahani (2012), in her article titled The status of women in the Philippines: a 50-year retrospective, stated that the functional literacy rate among women from 19892008 was $3.47 \%$ higher than male; yet the employment rate among women was $30.74 \%$ lower than men. There are increasing numbers of sexually harassed and abused women despite the passage of Anti-Trafficking in Persons Act in 2003. The law exists yet it does a very little impact on the real situation of Filipino women. Moreover, House Bill 267 or the Anti-Discriminatory Bill on the Basis of Sexual Orientation and Gender Identity took 17 years before it reached the Senate plenary under the name called Senate Bill 1271. This Senate Bill "seeks to protect the LGBTQ community in the country." The discussions and negations in passing this bill are far from over yet. The country's prevailing catholic conservatism sparks several controversies. Senators and congressmen argue with their conflicting opinions, while the religious community says it is against the rule of the church. The Philippine's system of gender qualifications still excludes the non-binary people.

In the academe, numerous gender studies have been done on books of poetry, essays, short stories, novels, and plays, finding the lost voices of women; but very few critical studies have been done on textbooks. Queer theory is also entering the literary mainstream; yet genderqueer and gender nonconforming characters still, have not penetrated the academe through textbooks. If they do, their presence is almost insignificant. Gay and lesbian poetry, short stories, novels, and even films are continuously being published yet textbooks still subscribe to the canonized body of literature and deprive the said types of literature inclusion.
According to Frasher and Walker (2013) and Peterson and Lach (2006) gender portrayal in textbooks reflected social values and behaviour. It worked in two ways. Textbooks were structured by the kind of society where it belonged. On the other hand, textbooks shaped the younger generation. In a book titled Promoting Gender Equality Through Textbooks: A methodological guide, it is stated that "a textbook is a basic learning tool for [students] and teachers, a tool of negotiation between the various actors involved in its production and use; and an element of communication within families, especially for values" (Brugeilles, 2009). United Nations Educational, Scientific and Cultural Organization's account on the new approaches in studying gender representations claims that the characters in textbooks, who have assigned skills, roles, statuses, ways of acting and attributes, contribute much in an individual's way of discovering what it means to be a woman, a man, a girl or a boy in a given society. If gender inequality or sexism is present in the textbooks used in Philippine public schools (with an estimated 8 million enrolled students), our country will still be dominated by the patriarchy not just in this generation but will continue in the succeeding generations.

It is quite disturbing to note that the textbooks, which are the most effective instruments in honing desirable attitudes and help students conduct themselves as gendered individuals, contain gender biases. D. Ashley Stockdale (2006) of the University of Birmingham found out in his study titled Gender Representation in an EFL Textbook that there was an imbalance in the gender representation in the textbook analyzed. She examined the representation of men and women in an English as a Foreign Language (EFL) textbook by focusing on the visibility of males and females, firstness, nouns and pronouns used to describe them, discourse roles, appearance in photographs, gender focus of textbook themes, and the amount and type of talk.

Arta Toci and Melek Aliu (2013) also discovered that the three different books used for beginner, pre-intermediate and intermediate levels in elementary schools in Macedonia demonstrated stereotypical representations of the two genders. The researchers checked the ways the books present females and males in terms of profession, appearance, sport/hobbies, personality traits, family roles and house work. This led them to the conclusion that the books investigated present children to biased information when considering 
professions. Both female and male were found in traditional roles, hobbies and tasks.

In the Philippines, one of the very few studies done on sexism in Philippine English Language textbooks was written by Veronico N. Tarrayo, a faculty of Arts and Letters in the University of Sto. Tomas. His study, Gendered Word (or World): Sexism in Philippine Preschool English Language Textbooks, explored the issue of sexism in six Philippine preschool English language textbooks. Adopting a qualitative-quantitative approach in examining gender visibility (illustrations), firstness, occupational role representation, character attributes, and interests and lifestyles, the data gathered revealed that the textbooks feature both genders yet males appeared more frequently than females in illustrations and they also mentioned first in most sentences and passages. Females were usually attributed with their good looks and passivity and represented in indoor activities, while males showed aggression and dominance. The researcher found the textbooks to be favoring males and thus considered to be sexists.

The critical lenses on textbooks are focused only on gender-binary issues. Gender-inclusivity remains impossible to penetrate the academe. Julia R. Temple (2005) conducted a study that examined the possible presence of genderqueer issues on textbooks. The researcher used content analysis to find if there were matters that deal with sexuality, relationships, and queerness in the 20 selected high school textbooks and found out that only $5 \%$ of those textbooks she coded made reference to queerness. It was noted that despite the presence of same-sex issues, same-sex sexuality in the textbooks was only limited to homosexuality that fall into queerness were hardly evident.

The long-standing clamor for gender equality remains unheard. Inspite of many local and international efforts made in the field of equality and human rights, women continue to be dominated by men. Gender bias is still present not just in homes and work places but also in schools and universities for most of the textbooks and other reading materials, which play an ever-increasing influence on gender development, are charged with sexism or gender imbalance.

This research challenged what the Department of Education states in its mission, “... to promote... [a] complete basic education where: Students learn in a child-friendly, gender sensitive, safe and motivating environment." Anchored on the principles of gender schema theory, a cognitive theory that explains how individual becomes gendered in an environment she or he is part of (Williams, 2017), this study investigated the gender representation and gender stereotypes present in the K-12 English learner's materials through triangulation and integration. The content analysis was also done under the critical lenses of Thomas D. Steensma's (2012) notion of gender discomfort and Jessica Xavier's (2006) gender variance model.

\section{Statement of the Problem}

The researchers intended to identify the gender representation and gender stereotypes present in the following learner's materials (LMs): English 7: English Learning Package; English 8: Voyages in Communication; English 9: A Journey Through Anglo-American Literature; and English 10: Celebrating Diversity Through World Literature. It looked into the female and male characters and their frequency of appearance in the books; female and male social domestic roles; their semantic roles, the order of appearance, and pictorial representation of both males and females.

Specifically, the researchers sought to answer the following questions:

1. How are genders represented in the $\mathrm{K}-12$ English learner's materials for Junior High School in terms of the following categories?

1.1 visibility in texts and illustrations

1.2 firstness

1.3 verb association

1.4 gender variance

2. What are the gender stereotypes present in the K-12 English learner's materials for Junior High School in terms of the following categories?

\section{1 occupation}

2.2 personality traits

2.3 domestic roles

\section{Methods}

\section{Research Design}

The researchers employed a critical exploration on the gender representation and gender stereotypes in the K-12 English LMs for Junior High School. This was achieved through a methodological triangulation specifically a within method, which involved both content analysis and interviews.

The summative content analysis was the guiding design for this study. This approach started with identifying and quantifying certain words or content in the text with the purpose of understanding how women and men were represented and stereotyped. The analysis focused on visibility, firstness, verb 
association, occupation, personality traits, domestic roles, and gender variance as its categories.

Visibility refers to the actual presence of female and male characters, both in text and in illustrations. The process of identifying female and male visibility required a methodical tallying of every appearance of a character according to their sex in all dialogs, texts, illustrations, and photos. For a textbook, not to have any gender biases, the number of female and male characters must be approximately equal (Kemp, 2014).

Firstness, on the other hand, refers to the total number of times a female or a male character appeared first in a text when both were presented in just a phrase or a frame. In this study, every incidence of female/male or male/female pairing were counted and tallied.

Analyzing the verb association in the learner's materials required a close investigation on how often a female or a male character were presented as an agent in every given sentence. This revealed if the stereotypes of women being engaged only in passive roles existed.

Furthermore, the occurrences of the characters' occupation were counted and tabulated. Then, these were subcategorized into skilled and unskilled. The analysis furthered taking into account the occupational gender stereotypes.

Personality trait refers to the enduring personal characteristics of an individual revealed in a particular pattern of behavior in different situations. Investigating the text under this category allowed the researcher to see if women or men were typecast in terms of personality traits.

Domestic roles refer to the function of a person relating to or involving her or his home or family. The researcher investigated the family roles or house work performed by female and male characters whether the roles were always associated with one gender over another.

Finally, gender variance or also known as gender nonconformity refers to a behavior or characteristics which cannot be pinned down as either male or female. Gender variance can be identified when a character explicitly say $z e$ is a gay, a lesbian, a transgender, or a gender fluid. The characters who manifested discomfort with their assigned genders could be considered gender variant or genderqueer. The character's manner of dressing, carrying oneself, and other behaviors might evince gender queerness as well.

To support the researcher's analysis of the learner's materials, interviews were conducted. The interviews inquired about the participants' familiarity with the LMs and their assessment and opinion about the presence of gender bias and stereotypes. The information which were driven from these interviews were juxtaposed and integrated with the results of the content analysis.

\section{Participants}

This study targeted both the English teachers and the Junior High School students as participants in the interviews. Out of 21 high schools and integrated high schools in the Division of City of San Fernando (P), four schools were randomly selected. From these schools, the researcher purposively selected eight English teachers (two for each grade level) and eight Junior High School students (also, two for each grade level). The criteria for the selection were: they must be teaching and using the K-12 LMs in English for at least a year; they must be a graduate of at least Bachelor in Secondary Education Major in English or any course in the field of language and literature; they must also have attended at least one Gender and Development seminar. Furthermore, the criteria for the selection of student-participants were: they must come from classes in which the K-12 English LMs were used as textbooks and not just as references; they must have been recognized as top achievers and must have exemplified good performances in their English classes.

\section{Instruments}

The researchers prepared two sets of questions for the interviews - one for the teachers and another for the students. Each set contained 10 questions, which inquired about the participants' familiarity with the learner's materials and their assessment and opinion about the representation of female and male characters and the presence of stereotypical characteristics of most female and male characters.

A tally sheet with guide questions were used by the researcher in analyzing all the learner's materials under study.

\section{Data Collection}

Both critical analysis and interviews were employed in gathering data. Using summative content analysis method, the gender of the characters presented in every textbook entry were identified. The analysis did not only consider both the literary pieces and the sentences under the language section. The illustrations of the materials, the gendered words used in the texts and those parts of the texts which deal with gender or gender equality were also identified. This method was also 
used to identify the amount of characters in different genders, the occupations they had, the actions they performed and other topics that rose from the texts.

The data gathered from the content analysis were substantiated by the information collected from the interviews. The researcher interviewed eight public school English teachers who had been in the service for at least one academic year. This was to ensure that the teacher had read thoroughly the content of the English learner's materials. The interview inquired about the teacher's observations and evaluation of the English LMs in relation to the possible presence of gender-stereotyped characterizations and gender biases.

The students were also interviewed. Prior to the interview, the students were asked to do advance readings since this study was conducted during the first and second quarters of the academic year. The questions the researcher asked were focused on the behaviors and the roles of both female and male characters the students encounter in the stories/texts from their English LMs.

\section{Data Analysis}

The researcher employed a critical analysis of the K-12 LMs. All the relevant words were identified as either masculine, feminine, neutral, or genderqueer and as stereotypical or nonstereotypical as prescribed in the conceptual framework. After close reading the texts in the K-12 LMs and after the content enquiry, the researcher made a list of the ratio of male and female characters, the gender firstness, verb association, their occupation, their personal traits, their domestic roles, and the indications of gender variance. To identify the gender representations in K-12 LMs, the researcher looked for the proportions of each item in each classification. However, the researcher checked if the occupations, personal traits, and domestic roles the female or male characters took were bounded by what the norms dictate to see if gender stereotyping and gender nonconformity were present in the LMs. The results of this critical analysis were juxtaposed and were integrated with the answers of the participants in the interviews. The themes that emerged from the responses of the teachers and student participants were classified into gender representation, gender stereotypes, and gender variance.

\section{Results}

The content analysis performed to identify the representation and stereotypes of the gendered characters in all K-12 English learner's materials for Junior High School focused on visibility, firstness, verb association, occupation, personality traits and domestic roles.

\section{Visibility}

In the texts and the illustrations present in the K-12 English LMs, male dominance was striking. The number of male characters amounted to $64.83 \%$ of the 2030 total number of characters. Females, on the other hand, accounted for $35.17 \%$.

\section{Firstness}

Analyzing the order of mention, the results obtained showed that male-first mention occurred more often than female-male pairings. English 7 and English 9 LMs contained the highest percentage of male-first mentions which occurred in $73.91 \%$ and $75.00 \%$ respectively. Female-first mentions in the English 10 LM occurred $34.66 \%$ less than the male-female pairings. Of the four LMs, English 8 LM had the least disparity between the two mentions. With only $4.7 \%$ difference, male-first mentions occurred more often than female-male pairings.

The pronoun parings such as he or she, he/she, and $s / h e$ were not counted for these were considered gender sensitive pronouns and these did not represent either a male or a female character. For instance, in this sentence found on English $8 \mathrm{LM}$ page 4-Politely ask your partner a question if you want to clarify something or want more information on what s/he said - the pronoun s/he refers to the antecedent partner. This is a common noun, which can either be a male, a female, or a genderqueer. On the other hand, gender neutral pronouns or gender inclusive pronouns such as zie, sie, or ey were not found in any part of the four K-12 English LMs.

\section{Verb Association}

In analyzing the verb association, the semantic roles of female and male characters were identified. The results showed that discrepancy between the percentages in every semantic role the characters take was apparent. Male characters, compared with female characters, appeared more often as agents by $20.78 \%$ and as experiencer by $2.46 \%$. As theme and beneficiary/recipient, the passive roles, male characters led by $2.46 \%$ and $0.92 \%$ respectively.

The semantic roles taken by the gendered characters were further classified into active and passive roles. $49.85 \%$ of 977 characters involved in actions were male characters reflected as active doer of the verb (The term active does not refer to 
the voice of the verb but to how active the character performs the action. Active roles are the semantic roles agent and experiencer.) in the sentences and passages found in the four K-12 English LMs. This was the category which received the highest appropriation among the semantic roles. This was also $23.24 \%$ higher than female characters reflected as active. $15.56 \%$ of the male characters were engaged in passive roles while $7.98 \%$ were female characters affected by the verb or receiving the action or object.

\section{Occupation}

The occupations of female and male characters were classified into 10 job groups, which was based on the International Standard Classification of Occupations (ISCO). The analysis revealed that male characters were often associated with skilled and high income-generating jobs, while female characters were associated with unskilled and lowincome generating jobs. $22 \%$ of the male characters were engaged in managerial occupations while $44 \%$ were engaged in professions such as Science and engineering professions; health professions; business and administration professions; and legal, social, and cultural professions. On the other hand, only $2(4 \%)$ of the female characters were engaged in managerial occupations. One was a legal marketing head and the other was a former president of the Philippines. Female characters engaged in professions were $10 \%$ higher compared with males. Most of them were found to be engaged in teaching and social and cultural professions. They also dominated in the following job groups: clerical and support group which was $3.33 \%$ higher than males, plant and machine operators and assemblers group surpassing males in $2 \%$, and elementary occupations group with $26 \%$ compared to male characters with only $6.67 \%$. Among these elementary occupations were maidservants, house helpers, and waitresses. Other job groups in which male characters led are: technicians and associate professionals group with $0.67 \%$ over females; service and sales workers group with $7.33 \%$ higher; skilled agricultural, forestry, and fishery workers which was $4 \%$ over female characters; craft and related trades workers group with $2.67 \%$ difference; and armed forces occupations group with $2 \%$ discrepancy when compared with female characters.

The list of occupations was further classified according to occupational gender stereotypes. The analysis of data revealed that male characters who were engaged in stereotypical occupations was strikingly high with $59 \%$. Only $14 \%$ of the total occupation occurrences were females in stereotypical occupations. In terms of nonstereotypical occupations, female characters had the least amount of percentage with only $8 \% .12 \%$ of the female characters were found in nonstereotypical occupations. Female and male characters who were engaged in occupations dominated by both men and women were also in $8 \%$.

\section{Personality Traits}

Gender biases can be manifested through the personality traits attached to a particular character. In the investigation of desirability and undesirability of the characters' personality traits, it was found out that male characters were almost equally presented in both personalities, $35.24 \%$ were portrayed with positive traits and $33.33 \%$ were depicted with negative traits. Moreover, most of the female characters, in $19.05 \%$, were described with undesirable traits, while only $12.38 \%$ were depicted with desirable characteristics.

Taking each gender stereotypes into account, most of the male characters were presented in stereotypical and stereotypically capable personality traits with a total of $40 \%$. Female characters, on the other hand, were almost seen in both traits almost equally: $15.24 \%$ in stereotypical and stereotypically capable traits and $16.19 \%$ in non-stereotypical and stereotypically less capable traits. These illustrate that the K-12 English LMs were sensitive in presenting female characters in terms of personality traits; yet fell short in considering male characters.

\section{Domestic Roles}

The K-12 English LMs for Junior High School had placed female characters almost exclusively in charge of the household responsibilities. They cooked, cleaned, and took care of the children, while male characters were involved in domestic roles only because no woman was present to take charge. Male characters did not take equal part in the household responsibilities. Women characters were discriminately bounded to fulfill the duties at home. Female characters in all the K-12 English LMs (in exception of the character Mama Lena from the story A Raisin in the Sun on pages 431-434 of the English 9 LM) were never seen making decision for the family. Mama Lena only took the responsibility of decision-making for the family because her husband was already dead.

\section{Gender Variance}


The analysis uncovered that there were no explicit evidence of gender variance or gender nonconformity among the male and female characters in the four K-12 English LMs. Thus, genderqueer characters were excluded from the LMs.

\section{Emerging Themes from Interview Responses}

\section{Gender Representation}

All the participants said that male characters took the major roles in the stories found in English LMs. Female characters on the other hand, took the supporting roles. These were aligned with the findings in the investigation of verb association. Male characters were more active than female characters because they led in the stories. Furthermore, the participants agreed that the English LMs presented the conditions of women in the society but not their contributions. They mentioned that the LMs raised the issues of arranged marriage, females bounded by their procreation duty, and the unfair treatment against them. Only Teacher-participant 3 made mention of a character who exemplified the modern women- a character who possessed and extraordinary courage to sacrifice her life for her father. They also agreed that there was an imbalance in the representations of male and female characters. Thus, the participants believed that the K-12 English LMs did not promote gender equality among the readers and/or the students.

\section{Gender Stereotypes}

In terms of gender stereotypes, the participants enumerated some of the stereotypical male and female characteristics which they had encountered in the texts. According to them, male characters were often associated with the characteristics like strong, independent, and high-and-mighty; while female characters were often associated with descriptions like quiet, shy, and weak. They had also noticed that female characters were attached with negative traits. Positive behaviors, on the other hand, were given to male characters. These were exactly the findings gained from the content analysis on the character's personality traits. The positive female characteristics which the teacher identified were often associated with their roles as mothers. They said that female characters were good and loving mothers. Although, there were some characters who they mentioned, those that defied the stereotypes such as Daskol, Ko-Ngai, and Juliet, they had not seen any explicit derogatory statements about genders. Teacher-participant 1 said that depriving the female characters of unbiased descriptions is a form of derogatory remarks. On the other hand, Teacher-participant 8 stated that she wasn't able to see derogatory statements in general, only for specific characters. They fell short in noticing those few that were identified from English 8 and English 10 LMs, because identifying them requires close reading of the entire LMs.

The student-participants' responses also revealed that in terms of characteristics and behaviors, roles, and occupations male characters ruled. According to the students, they were often described as strong and brave, while female characters were weak, domestic, and loving. Also, students observed that most of the female characters took only the supporting roles, compared with male characters who always were the heroes in every story. In terms of occupations, male characters were often seen as the head, while female characters appeared as mothers most of the time.

\section{Gender Variance}

There were no signs of gender variance in the four K-12 English learner's materials used in Junior High School. The participants said that they hadn't noticed any character who could not be considered a male or a female. There were no indications of genderqueer individuals such as gays, lesbian, genderfluids, and polygenders.

\section{Discussion}

The results obtained through the content analysis and the emerging themes from the interviews conducted reaffirmed what the previous research findings suggest. Past researches have shown that sexism exist in the textbooks used in most schools and universities, not just in the Philippines but also in most part of Asia and Europe. Males are represented superior in most textbooks (Lee, 2014).

Disparities existed in the representation of female and male characters in the K-12 English LMs. Male characters appeared more often in the texts. They also appeared first in most gender pairings. The dominance of male characters through the striking presence of male-first mentions were reinforced by the occurrence of the following disturbing observations. First, was the use of pronoun he to refer to gender-neutral nouns. On page 2 of the English $8 \mathrm{LM}$ for instance, the sentence-Discover literature as a means of understanding the human being and the force/s he has to contend with-used the pronoun he to refer the antecedent human being. Another instance in 
which the masculine pronoun he was used to refer to a gender-neutral noun Filipino was found on page 22 of the English $8 \mathrm{LM}$. In addition to these, the pronoun it which was used to refer to a singular object was used to replace the antecedent girl. On page 417 of the English 9 LM, character Higgins stated, ... "and I'm not going to waste another cylinder on It (To the girl)." These instances subconsciously reduced the value of women to just merely an object.

Another trend found in the critical data and in the interview-responses was the female characters' lack of involvement in active roles. Although some of the female characters could be seen in aggressive and bold acts such as command, expose, refuse and accuse in some parts of the LMs, most of them were deprived of active role participation and only appeared as object of the verb, object of the preposition or as subject of a linking verb. In the first story of the English $7 \mathrm{LM}$ where a female character was first introduced, Alunsina appeared in this sentence-- ... it is related that Tunkung Langit fell in love with Alunsina-- as object of the preposition with. Likewise, in the story Hands of the Blacks from English $8 \mathrm{LM}$, the persona's mother was introduced in this sentence-My mother is the only one who must be right about this question of a black's hands being lighter than the rest of his body. The female character, which also was deprived of name, was only associated with the linking verb $i s$.

Also, an alarming fact found in the LMs was the absence of gender variance. J. Temple (2005) found out in her study that queerness was still far from being accepted in the society and so as in the academe. Years have passed and this remains to be true. There was no indication of gender nonconformity in any of the four K-12 English LMs. There were no characters who exhibited discomfort in their assigned genders or who wished to be in other gender. There were few characters which displayed inclination towards gender variance, because they showed non-conformity only in one or two categories in Xavier's (2006) gender variance model. In terms of occupations, there were few who were found in non-stereotypical occupations such as a male clerk or a female naval commander. In terms of grooming, there was one character in English 9 LM who showed fluidity in representing herself. On page 369, Liz was described as unpredictable because she would "dress kind of skater-ish, in camouflage pants, sweatshirts, and wristbands" but sometimes would "wear overalls or fancy dresses." Since gender variance is not only based on occupations or physical appearance, these characters were not considered gender-variant.

It has been consistently shown in this research that gender stereotyping was present in the K-12 English LMs. Anthropomorphized male main characters in assertive characterization still exist in textbooks despite a decade of studies on gender representation and stereotypes (Aliu, 2013). Although in this research there were attempts to defy the female and male stereotypes, most of the characters were still typecast in terms of occupations, personality traits, and domestic roles.

The results revealed that only few female characters were projected in occupations. Most of them were just pigeonholed as mothers, daughters, and/or sisters. Those female characters who were engaged in occupations were only associated with jobs such as maids, secretaries, or as waitresses. For instance, in the stories found in English $7 \mathrm{LM}$, almost all the female characters including Alunsina, Nana Emilia, Baldo and Leon's mother, and Mr. Libre's wife (not even called Mrs. Libre in the story) stayed at home, did the household chores, and waited for their husbands to come home. English 7 and $8 \mathrm{LMs}$, which were published earlier than the LMs used in Grades 9 and 10, failed to present the female characters in occupations that were not traditional for women. The LMs for Grades 9 and 10, which showed sensitivity to the issues of discrimination, not particularly gender-linked discriminations, attempted to engage female characters in jobs that were traditionally for men. Though this did a little impact on the overall gender representation in terms of occupational roles, this attempt to put some of the female characters as well as some of the male characters out of their stereotypes was of great value, because challenging the norms even in smaller scales was still a brave act defiance.

In terms of desirability of personality traits, female characters were found to be discriminated while male characters were not. They were often associated with negative traits, while male characters were often associated with positive traits. In terms of gender-linked personality traits, female characters defied the stereotypes while male characters did not. Furthermore, domestic roles were almost exclusively attached with female characters. There were very few male characters who were engaged in domestic or household roles. They were only engaged because of the absence of female characters to do it. 
The findings in this study contributed to the understanding that mainstreaming gender balance and gender inclusivity in all learning avenues, including the learner's materials, is of great value. Awareness on gender representations and stereotypes in K-12 LMs would help the Department of Education to be more vigilant in constructing and providing educational materials for the students. It might also help the department create a program that would address the issues of gender inequality and sexism not only in the LMs used but also in all learning materials they provide both private and public schools. Being the first critical and comprehensive gender study on the K12 LMs and the first that explored the possible presence of gender variance or gender nonconformity in the LMs, this research might serve as a guide in furthering and enriching the researches in Philippine textbooks, K-12 LMs, and so as about gender representation and stereotypes.

\section{Conclusion}

In conclusion, imbalance in gender representation and gender stereotyping are present in the K-12 English LMs used in Junior High School. Male characters showed far more visibility than female characters. Although in the K-12 English 8 LM female-first mention occurred more frequently, the male-first mention dominated in the four K-12 English LMs. The analysis of the verb associations uncovered a disturbing fault in the LMs wherein male characters were engaged in more active roles than female characters. They were often portrayed in passive roles and were almost pinned down on the margins, barely noticeable. Moreover, any indication of gender variance or gender nonconformity in the four K-12 English LMs was not found.

In terms of occupation, male characters were engaged in them more often than female characters. Most of the female characters were projected only as mothers or wives. Those who were engaged in occupations, were often associated with those that required less knowledge-based skills and were lowincome generating. However, male characters were often linked with occupations that required leadership and knowledge-based skills and were high-income generating. Female characters were found to be discriminated when desirability of personality traits was taken into consideration. They were often associated with negative traits, while male characters were often associated with positive traits. In regard to gender-linked personality traits, female characters defied the stereotypes while male characters did not. Furthermore, domestic roles were almost exclusively attached with female characters. Male characters engaged in domestic roles because of the absence of female characters to do them.

Given the results obtained from this study, the researchers suggest that the selection of the literary pieces in the K-12 English LMs may be reconsidered. Although it would be impossible for the writers to disregard the literary canons, there is still a rich collection of literary pieces which feature female characters or heroes. Works of female authors who penetrated the literary canon may also be considered in the selection. This will allow the readers to see the world not just in men's perspective. Writers and editors may also be very cautious in terms of order of mention when writing sentences in the language or grammar sections of the LMs. This way, they can create a balance in the representation of the female and male characters.

The inclusion of sentences or passages which highlight women or stories where female characters take the major roles may address the issue of imbalance in the presentation of characters in terms of verb association. Most of the sentences used in the language section of the four K-12 English LMs are usually taken from the reading texts. The writers and editors of these LMs may come up with new sets of sentences and paragraphs where females act as the doer of actions. It is an inescapable fact that most of the literary pieces commonly chosen to be included in textbooks are dominated by male characters. Yet, there is still a wide range of feminist and genderqueer literary pieces to choose from. Replacing some of the passages in the LMs with pieces from feminist and genderqueer literature may allow readers and students to see female characters who are more engaged in maledominated occupations.

With regard to the issue of negative and stereotypical images associated with female characters present in the four K-12 English LMs, this may be addressed by providing tasks that may allow students to reflect on the images of both males and females. This may lessen the impact of gender stereotyping to the readers. The LMs may not only contain lessons on discrimination but may include gender discrimination in particular. This may allow the students to deeply understand that females are not born only to fulfill their domestic duties.

Including gay, lesbian, or genderqueer literature in the English LMs may also be taken into consideration. A particular lesson or section of the 
book may be allotted for the discussion of genders outside the binary and stories which feature genderqueer characters may be included. For the K12 English LMs to entail gender sensitivity and genderqueer inclusion, the Department of Education may require all textbook writers, editors, and publishing companies that work for the department to engage in seminars and trainings on gender sensitivity and inclusivity.

Finally, the future researchers may conduct more studies on gender representation and stereotypes in other textbooks and LMs used in the schools, colleges, and universities in the Philippines. They may also consider investigating gender sensitive and gender inclusive teaching strategies used in the academe to supplement the sexism found in the LMs. Continuous conduct of studies in this field may place gender sensitivity and gender inclusivity in the mainstream.

\section{References}

[1] Aliu, M., \& Toci, A. (2013). Gender Stereotypes in Current Children's English Books Used in Elementary Schools in the Republic of Macedonia. American International Journal of Contemporary Research, 3(12), 32-38. Retrieved from http://www.aijcrnet.com/journals

[2] Barozzi, S., \& Ojeda, J.R.G. (2016, January 25). Sexual Identities in EFL at Primary School Level: A Pre-service Teachers' Perspective from Spain. Porta Linguarium. Retrieved from http://ugr.es

[3] Brugeilles, C. (2009). Promoting Gender Equality Through Textbooks: A Methodological Guide [e-book]. Retrieved from http://unesdoc.unesco.org

[4] Kemp, N. (2014). A Gender Analysis of the ESL Textbook Side by Side. Kyushu International University Journal, 217-233. Retrieved from http://ci.nii.ac.jp/els

[5] Lach, S. B. (2006). Gender Stereotypes in Children's Books: Their prevalence and influence on cognitive and affective development. Gender and Education, 185-197.

[6] Lee, J. F. (2014). Gender Representation in Hongkong Primary School ELT Textbooks: A Comparative. Gender and Education, 356-376.

[7] Saarikivi, K. (2012). Gender Representation in the Finnish EFL Textbook Series The News Headline and Smart Moves (Master's thesis, University of Tampere, Finland). Retrieved from https://tampub.uta.fi
[8] Shahani, L. R. (2012, October 3). GMA Network. Retrieved from http:// www.gmanetwork.com

[9] Steensma, T. D. et.al. (2013). Gender identity development in adolescence. Hormones and Behavior, 288-297.

[10] Stockdale, A. (2006). Gender Representation in an EFL Textbook (Master's thesis, University of Birmingham, United Kingdom). Retrieved from http://www.birmingham.ac.uk

[11] Tarrayo, V. N. (2014). Gendered Word (or World): Sexism in Philippine Pre School English Language Textbooks. i-Manager's Journal in English Language Teaching, 25-32.

[12] Temple, J.R. (2005). People Who are Different from You: Heterosexism in Quebec High School Textbooks. Canadian Journal of Education. 28(3).

[13] Walker, F. A. (2013). Sex Bias in Children's Books. Childhood Education, 220-222.

[14] Williams, Y. (2017). Gender Schema Theory: Definition and Explanation. Retrieved from http://study.com/academy/lesson/genderschema-theory-definition-lesson-quiz.html

[15] Xavier, J. (2006). Transgender Identity: Gender Variance Model. Retrieved from http://www.gender.org/resources/dge/gea02006 .pdf 